\title{
Postvasectomy Semen Analysis: Are Men Following Up?
}

\author{
Ronald E. Christensen, MD, and Dalton C. Maples Jr., PA-C
}

Background: Many family physicians perform outpatient vasectomies in their office. Postvasectomy semen analysis (PVSA) is critical to establish the success of this sterilization procedure. We investigated the compliance rate of our patients with the PVSA over a 10-year period.

Methods: To determine compliance rates of men who have undergone vasectomy for recommended PVSA, a retrospective chart review in a private family practice clinic was performed. The records of all patients who underwent vasectomy from 1991 to 2001 were reviewed. Patients are instructed to return at 6 weeks, 3 months, and 1 year for semen specimen evaluation to determine vasectomy success.

Outcome Measures: Records of 551 patients were reviewed. The age of the patient at the time of the vasectomy and number of PVSAs were evaluated. PVSA compliance rates were also correlated with age.

Results: In total, 233 (42\%) men did not return for 6-week, 3-month, or 1-year PVSA. Of 551 men, 318 (58\%) returned for 6-week PVSA, and 138 (25\%) returned for 3-month PVSA. Only 44 (8\%) of the 551 eligible for a 1-year analysis returned for PVSA.

Conclusions: Compliance with instructions to men undergoing vasectomy to return for PVSA is low both from the perspective of this study, as well as other studies evaluated. Older men are more likely to return for PVSA. (J Am Board Fam Pract 2005;18:44-7.)

Male sterilization through vasectomy has become one of the most popular and safest means of birth control in the United States today. Approximately $12.6 \%$ of women using any of the available means of contraception in the United States are protected by their partners' vasectomies. ${ }^{1}$ Implementation of the No Scalpel Vasectomy (NSV) procedure has reduced the time required for the vasectomy procedure and also has reduced postvasectomy complications. ${ }^{2}$ As a part of the procedure, the patients and partners should be counseled on the importance of follow-up semen analysis. Confirmation of successful vasectomy should be accomplished through 2 consecutive azoospermic specimens. ${ }^{3}$ In most men, azoospermia is achieved within 4 to 6 months of vasectomy. ${ }^{4,5}$ Many men do not return for postvasectomy semen analysis (PVSA), which could leave their partners at risk for unplanned pregnancy and surgeons at risk for litigation. The purpose of this retrospective study was to review

Submitted, revised, 6 September 2004.

From Independence Park Medical Services, Anchorage, $\mathrm{AK}$, and private practice, Anchorage, AK. Address correspondence to Ronald E. Christensen, MD, Independence Park Medical Associates, 9500 Independence Drive, Anchorage, AK 99507. patient compliance with instructions to return for PVSA in one family physician's private practice office.

\section{Patients and Methods}

Participants in this study consist of all men who underwent vasectomy at Independence Park Medical Services between 1991 and 2001. A single family practice physician provided the prevasectomy consultation, performed the surgery, and provided the postvasectomy follow-up. Patients were requested to bring their spouse or significant other (if they had one) to the prevasectomy consultation appointment.

During the initial consultation the candidates were questioned about reasons for their decision for vasectomy, number of children, desire for more children, and happiness in their current relationship. Patients were examined to rule out physical problems that might disqualify them from having a vasectomy. A diagram of the male reproductive tract was used to show the patient how the male reproductive system works and what will be done during the surgery. Risks of the surgery were explained, and the patient was questioned to make sure that he understood the information. They 


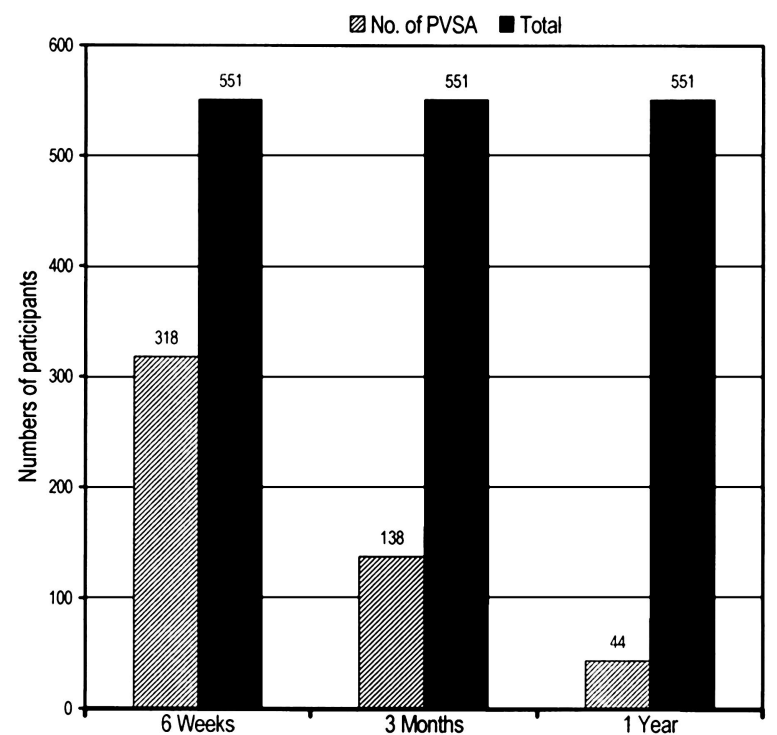

Figure 1. Total vasectomies compared with number of PVSAs.

were instructed that on the day of the surgery they should bring an athletic supporter and someone to drive them home. The men were also told to use an ice pack on the scrotal packing for 12 hours, to lie down for the first 12 hours after surgery, and to avoid heavy lifting for 72 hours postvasectomy to avoid complications. Patient education pamphlets were given to each candidate for further reading. Instructions for PVSA requirements were given both at the time of the procedure and in a follow-up phone call the next day.

Patients were informed that approximately 20 ejaculations or 12 weeks are usually required to deplete the sperm from the ampulla of the vas deferens and to ensure a negative PVSA. ${ }^{6}$ The men and spouses (or significant others) were asked to return for PVSAs at 6 weeks, 3 months, and 1 year. They were told that there was no additional charge for the PVSA and that it was included in the cost of the surgery. The importance of the PVSA was stressed, emphasizing that until 2 consecutive negative PVSA specimens are accomplished, condoms and or other forms of birth control should be used. Patients were told that microcannulization or 'bridges' could spontaneously develop between the cut ends of the vas deferens or even the presence of a third vas deferens might be the cause of vasectomy failure. Surgical technical failure was also discussed as a possible cause.

At the end of the appointment, the couple or individual was given a pamphlet that covered all the information that the physician discussed during the appointment. They were asked to sign a vasectomy request/consent form acknowledging that they understood what was discussed with them. The original was placed into the chart and the patient was given a copy, as well as a copy of an article on the "No Scalpel Technique Vasectomy."

Records of 551 patients receiving vasectomies from 1991 to 2001 were reviewed retrospectively. Records were evaluated for patient age, number of children (including children from other relationships), number of 6-week, 3-month, and 1-year PVSAs. Exemption status from full Institutional Review Board review was petitioned and approved by the University of Alaska Institutional Review Board.

\section{Results}

Findings from chart evaluations revealed that of 551 men, 318 (58\%) returned for the initial 6-week PVSA, and 138 (25\%) returned for the 3-month PVSA. Only 43 of 551 men (8\%) returned for the 1-year PVSA (Figures 1 and 2).

All charts of 551 men were examined for the patient age at vasectomy, and the numbers were used to determine compliance rates. The rates of PVSA by age are presented in Figure 3. It is appar-

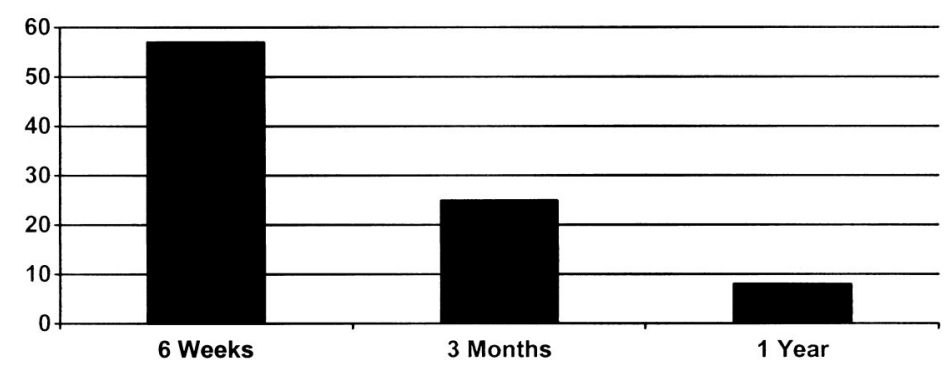

Figure 2. Overall percentages of participants returning for PVSA. 


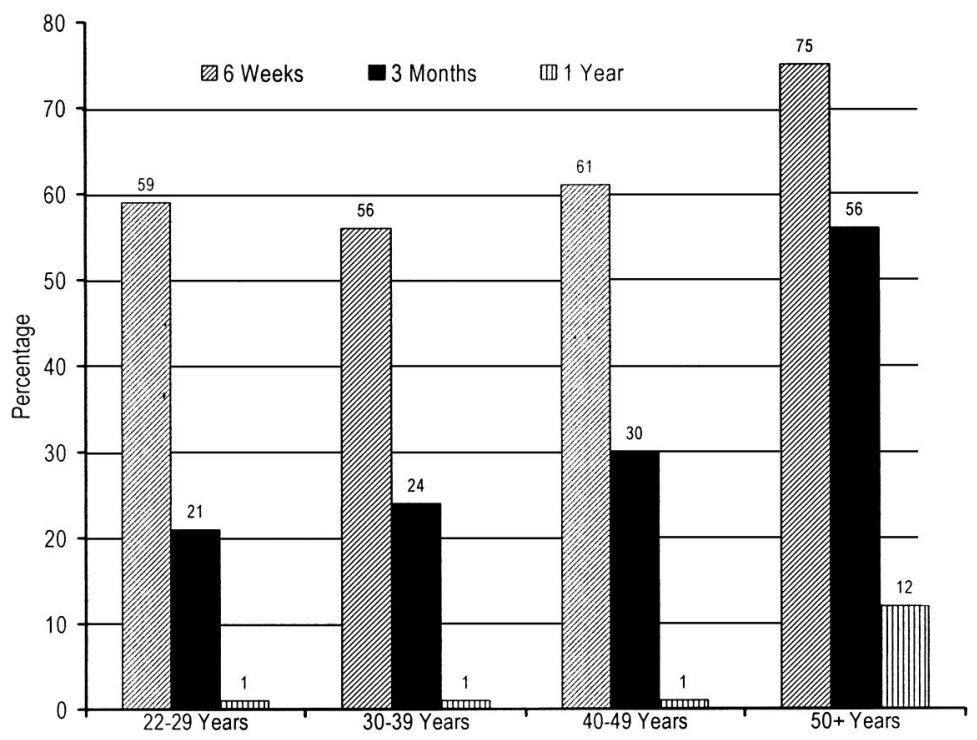

Figure 3. PVSA follow-up rates (\%) by age group.

ent that a larger proportion of older men returned for PVSA.

\section{Discussion}

The results indicate that the overall rates of compliance with instructions to return for PVSA were low. Compliance in a similar study in the United Kingdom of 240 men showed that 206 (86\%) returned one specimen, 184 (77\%) returned 2 samples, and 34 (14\%) failed to return any specimens. ${ }^{7}$ Another study of 1892 men was done at the Michigan Urological Clinic from 1985 to 1995 . Results showed 619 (33\%) returned for one PVSA, and 644 (34\%) never returned with any follow up specimens. ${ }^{8}$ Thus, the published studies and the current study all resulted in reports of low rates of return for PVSA.

Neither the United Kingdom study nor the Michigan study provided information on PVSA by age groups. The age of the men and the greatest potential for impact on their lives with an unplanned pregnancy may be a factor. In the current study, the $50+$ group seems to be the most compliant with recommendations for PVSA.

In another study from the Family Practice Center of the Medical College of Ohio, patients were given preoperative counseling, physical examination, and explanation of procedures, as well as postoperative directives. They were also given instructions on collection methods, 2 sterile containers, and instructed to drop off specimens within 3 hours. ${ }^{8}$ Compliance in this study was similar to that in other studies: $45 \%$ the men returned no samples, $29 \%$ returned with one specimen, and $26 \%$ followed up with 2 or more. ${ }^{9}$ These men also received questionnaires requesting information about PVSA and how they felt. The results of the questionnaires revealed the men felt inconvenienced, embarrassed, forgetful, or certain of sterility. Other confounding aspects may be the patient's feelings of potential embarrassment, understanding of collection options for the sample, remembering the dates for PVSA, and timeliness of sample delivery to the laboratory.

The Michigan Urological Study listed 10 theoretical reasons why men did not return for followups:

1. Death of the patient or partner.

2. Change in the patient-partner relationship (eg, divorce or separation) making fertility status less important.

3. Change in fertility potential of the partner (eg, hysterectomy, oophorectomy, or illness affecting fertility potential).

4. Patient leaves geographic area.

5. Patient changes physician or health plan.

6. Patient does not understand the postvasectomy follow-up instructions.

7. Patient fears the results of semen analysis.

8. Patient is unable to provide semen for analysis.

9. Semen analysis is lost or mishandled. 
10. Patient is able to perform his own semen analysis (eg, he is a physician, dentist, or veterinarian).

Our findings suggest that patient age is also an important determinant. Perhaps this is related to potential for greater impact of unplanned parenthood on his life at later age, which might include not only the unanticipated direct costs of raising a child but also changes in planned lifestyle goals, such as retirement.

\section{Conclusion}

Rates of compliance with instructions to return for PVSA after vasectomy are low in the current study and in other published studies. Age at the time of vasectomy may be an important determinant in compliance rates. Strategies should be devised to improve the rates of return for PVSA. These might include using reminder cards or phone calls at appropriate intervals or even sending the patient home after surgery with the first empty specimen container. Further studies should be aimed at determining which intervention techniques are most successful and practical.

We are indebted to Tom Norris, MD, Associate Dean, University of Washington School of Medicine, for his expertise and professional review of this article.

\section{References}

1. Haws JM, Butta PG, Girvin S. A comprehensive and efficient process for counseling patients desiring sterilization. Nurse Pracr 1997;22:6:52-8.

2. Stockton MD, Davis LE, Bolton KM. No-scalpel vasectomy: a technique for family physicians. Am Fam Physician 1992;46:1153-67.

3. Denniston GC, Pfenninger JL. Vasectomy. In: Procedures for primary care physicians (Pfenninger JL, Fowler GC, editors). St. Louis: Mosby; 1994. p. $520-40$.

4. Haldar N, Cranston D, Turner E, MacKenzie I, Guillebaud J. How reliable is vasectomy? Long-term follow-up of vasectomised men. Lancet 2000;356: 43-4.

5. Thompson B, MacGregor JE, MacGillivray I, Garvie $W H$. Experience with sperm counts following vasectomy. Br J Urol 1991;68:230-3.

6. Muirhead G. What's new in male sterilization. $\mathrm{Pa}$ tient Care 1999;33:143.

7. Bradshaw H, Rosario D, James M, Boucher N. Review of current practice to establish success after vasectomy. Br J Surg 2001;88:290-3.

8. Maatman TJ, Aldrin L, Carothers GG. Patient noncompliance after vasectomy. Fertil Steril 1997;68: 552-5.

9. Smucker D, Mayhew H, Nordlund D, Hahn WK Jr, Palmer K. Postvasectomy semen analysis: why patients don't follow-up. J Am Board Fam Pract 1991; $4: 5-9$. 